\title{
MEMÓRIA HISTÓRICA SÔBRE SÃO SEBASTIÃO (II).
}

\section{(Continuação).}

\section{DA PRESENÇA DE NAVIOS CORSÁRIOS EM SÃO SEBASTIÃO.}

Por várias vêzes temos feito referências ao pôrto de São Sebastião, não só por sua grandeza e profundidade, como também pela segurança do seu incomparável ancoradouro, que em todos os tempos serviu de refúgio às embarcações acossadas pelos temporais.

Protegido dos ventos do mar pela portentosa ilha do mesmo nome e possuindo duas barras francas, era natural que a êle se dirigissem os navios que navegavam pela costa paulista, servindo-se dêsse seio de Abraão, para o necessário repouso, depois de longas viagens e também para o natural reabastecimento de víveres e água.

Tais motivos levavam constantemente ao canal do Toque-Toque não só os navios mercantes, como também os brigues flibusteiros e corsários que cruzavam os nossos mares, pondo em sobressulto as populaçóes das vilas da marinha.

O aparecimento de tais embarcações diante da vila de São Sebastiäo era comum desde os primeiros anos da descoberta do Brasil, quando os celerados dos mares passaram a agir nas costas do Atlântico sul.

Sôbre êste assunto nos referimos em outro capítulo, tratando do assalto levado à vila pelos corsários argentinos.

Da presença de corsários estrangeiros, apresenta-nos o erudito dr. Afonso de E. Taunay em magnífico trabalho, publicado na $R \mathbf{R}$ vista do Museu Paulista, um substancioso estudo, interessante e circunstanciacia noticia que procuraremos resumir, acrescentando-lhe dois documentos inéditos, dos muitos que se encontram no Arquivo do Estado.

Diz o iluste historiador patrício que o fato vem narrado em um livro hoje raríssimo, que é a História da expedição de três navios enviados pela Companhia das Indias Ocidentais, das Províncias Unidas, às Terras Austrais em 1721, da autoria do viajante C. 
F. de Behrens, talvez o primeiro alemão que haja realizado uma jornada circunavegatória, como turista.

"Era mecklemburguez e desde os primeiros annos da razão, manifestou verdadeiro enthusiasmo pelas viagens, quando, aos cinco annos, realizou com os paes longa excursão pela Pomerania".

"Começou a carreira de viajante percorrendo as terras balticas. Depois de atravessar a Curlandia e a Livonia, esteve algum tempo em Petersburgo e Dantzig".

Viajou ainda por outros países e estando em Amsterdão, soube que a Companhia das Indias Orientais havia preparado uma expedição de três navios aos Mares Austrais, sob o comando do almirante Roggewyn, empenhando-se então para que o deixassem compartilhar da mesma, o que conseguiu, ingressando com o pôsto de sargento e embarcando na capitânea.

"A 16 de Julho de 1721 zarpou de Amsterdam a referida esquadrilha, composta de tres navios: "Aguia", capitanea, com 36 canhões e 111 tripulantes; "Tienhoven", com 18 peças e 100 tripulantes e a "Galéra de Africa", com 14 boccas de fogo e 60 marujos".

A viagem foi cheia de incidentes, tendo havido sério encôntro com cinco navios corsários, à altura das Canárias.

Depois passaram à vista das ilhas do Cabo Verde, atravessando a linha do equador.

A seguir foram avistadas algumas ilhas brasileiras, atingindo a esquadra o litoral paulista e dando fundo "na baía do Porto".

Apenas ancorado o "Águia", baixou a terra um escaler que levava um cadáver de marinheiro e devia abastecer-se de água e refrescos.

"Surgiu logo na praia um magote de portuguezes armados. Ordenou aos desembarcantes que estacassem sob pena de serem espingardeados. Como os hollandezes lhes mostrassem o defunto, amenizaram-se, chegaram á fala e indicaram um logar proprio para a desejada sepultura.

"Explicaram então que Porto era o então porto de S. Sebastião. Dependiam do governo do Rio de Janeiro, dalli distante oito milhas! Convindados a ir a bordo recusaram, in limine, a proposta. E com toda a razão; eram aquellas paragens muito visitadas por flibusteiros. Seis mezes antes appareceram uns, que se tinham posto a saquear, mas haviam tido tragico fim. Surgira um vaso francez que puzera o navio pirata a pique.

"Já o mesmo fizera com outro, perto de Catria (Santa Catharina) (?) .

"A carga do primeiro, avaliada em sete milhões desapparecera num logar onde só havia 13 braços de fundo. Mergulhadores tinham vindo expressamente de Por- 
tugal a ver se seria possivel salvar uma parte de taes riquezas.

"Seria o flibusteiro o famoso "Pamelar", habitué das aguas de São Sebastião e de quem muito falam os chronistas de São Paulo?

"A custa de muitos pedidos vieram dois portuguezes a bordo da capitanea, onde o almirante os tratou com a maior gentileza, enchendo-os de presentes.

"Prometteram em troca os obsequiadores pilotar a esquadrilha batava e, com toda a lealdade, cumpriram a promessa.

"O Porto, optimo ancoradouro, dava até 8 braças. Levantando ferro, entraram os navios no canal do Toque Toque, cujas margens estavam inteiramente desertas. Nas suas aguas apanhavam-se peixes e tartarugas, deliciosas, para grande alivio dos 40 escorbuticos que havia a bordo.

"Afinal, depois de uma navegação de 7 leguas ancoraram os neerlandezes, em frente a São Sebastião, salvando a terra tres vezes, com 7,5 e 3 tiros. Não foram as salvas contestadas. Talvez porque não houvesse em terra canhões em estado de falar, ou porque tomassem os sebastianenses, os recenvindos, por piratas.

"Mandou Roggewyn recado ao governador local. Pedia viveres frescos, agua, lenha, gado, fructas e licença para desembarcar os seus doentes que poderiam occupar casinhas a beira-mar. Respondeu-lhe s. s. que nada poderia prometter antes de obter do seu superior hierarchico, permissão para tanto. Ia pois enviar-lhe um proprio neste sentido.

"Furioso retrucou the o almirante com o distico que é a divisa da nação chilena. Ou por bem ou por mal...

"Em todo caso, notando que na villa havia um convento, achou de boa politica recorrer á intervenção eclesiastica á permissão do seu prelado, naturalmente homem de paz, a quem mandou uns presentesinhos.

"E a cousa calhou admiravelmente tanto mais quanto succedeu que o guardião (o cenobio era franciscano), vinha a ser um hollandez de Utrecht, certo frei Thomaz.

"Dentro em pouco, estava a bordo satisfeitissimo, em companhia de varios confrades. Vinte e dois annos havia que não falava a lingua materna! Sua commoção immensa sensibilizou os patricios. Agora sim, declarou, podia morrer contente. Avistara-se com compatriotas.

"Declarou Roggewyn, que estava disposto a obter em São Sebastião por la razon é la fuerza tudo de quanto precisava. Pediu lhe o guardião (a quem Behrens chama sempre o Prior), que tivesse paciencia por alguns dias.

"Em quanto não viesse a resposta do governador fluminense elle, guardião, abasteceria a nau almirante. E assim se foram de bordo os franciscanos.

"Notou Roggewyn, muito movimento de gente armada em São Sebastião.

"Indo um de seus escaleres buscar agua, soffreu uma surriada de mosquetaria. 
"De kordo contestada, dahi proveio a morte de dois portuguezes. Fugiram os demais e os batavos desembarcaram em attitude bellica.

"A vista deste incidente resolveu Roggewyn tomar a villa de assalto e movimentou os seus vasos em attitude aggressiva. Isto porém, mais como meio intimativo, pois receiava comprometter as relações amistosas, batavo-lusitanas, então reinantes.

"Surtiu o plario, excellente effeito e o vice governador (?) veio a bordo arrumar as cousas.

"Combinou que se fariam os fornecimentos livremente e prometteu castigar os autores da aggressão ao escaler. Explicou quanto viviam os sebastianenses suspeitosos dos extrangeiros. Não havia muito, em São Sebastião, estivera um navio francez que adquirira da gente do logar, fartos generos. Quando o pagamento lhe fora solicitado, promettera abrir fogo contra a villa.

"Tudo, porém, se concluiu admiravelmente, affirma Behrens. E na melhor ordem, harmonia e honestidade. Venderam os hollandezes suas mercadorias comprando em troca fumo, assucar, cereaes, aguardentes, fructos, animaes, etc.

"Nunca houve a menor duvida por causa destas transações. Os doentes restabeleceram-se logo, e os sãos divertiram-se, a tripa forra, com os portuguezes que os trataram admiravelmente.

"Assim, as nossas rusgas acabaram em amizade a ponto de, ao partirmos, vermos os portuguezes, de nós se despedirem chorosos. Afiançaram que jamais supporiam fossem os hollandezes, gente heretica tão boa e tão diversa dos francezes. Estes, alliás seus correligionarios, os haviam cruelmente maltratado.

"Dahi o temor com que a nossa chegada haviam procurado esconder o que tinham de melhor.

"Descrevendo São Sebastião narra Behrens que a cidade (etc.) dispunha de mediocre extensão. Pouco fortificada, era circumscripta por uma estacada, provida de alguns canhões. Possuia egreja assás bella e um palacio magnifico (?) de governo. Quanto ás casas dos moradores, sua construcção era a dos indios.

"No convento de S. Francisco, residiam 30 frades.

"Nelle sobresahia notavel curiosidade: certo idolo dos indios, estatua de uns quatro pés e meio de altura, e pé e meio de diametro. Tal figura, monstruosa, era meio leonina, meio tigrina. Embora lhe dissessem que de ouro massiço, pareceu a Behrens dourada apenas.

" $A$ ' cabeça trazia dupla corôa espetada de duas flechas ou dardos entre os quaes duas quebradas. Atraz se notava de cada leão uma aza semelhante ás das cegonhas.

"Curioso é que no interior da estatua se encontrasse outra representando um autochtono, trazendo ás costas um carcaz, cheia de flechas e ás mâos arco e flecha. Si assim era, como poderia ser de ouro massiço a estatua? 
"A cauda do tal idolo, muito longa, enrolava-se em torno da figura do homem armado. Tinha a ponta como a dos dragões.

"Ao idolo chamavam em São Sebastião Nasil Lichma (sic!?)

"Além desses jagodes guardavam os frades varias outras antiguidades europeias e americanas.

"O que o nosso Beherens inculca de geographia brasilica deixa muito a desejar. Segundo elle, as principais cidades do paiz eram Salvador (sic) capital, Olinta, Reiff, Siara, Seregipedel. Rey, S. Vicente Siara e Rio de Janeiro, (sic). Varias destas cidades fortificadas tinham bons portos. Quanto aos principaes rios do Brasil, vinham elles a ser o Mananhon e Tapicuan, o Mangnodaluis Bopa (sic) o São Francisco e o Janeiro" (22) .

Passando a outras informações de ordem geográfica e mineralógica, assegura Behrens haver apreciado imenso o clima da lacalidade, declarando serem os ares sobremodo salubres, mau grado a ocorrência, em determinada estação, de excessivos calores.

Depois de algum tempo de permanência,

"resolveu Roggewyn encurtar a estada em S. Sebastião e uma das causas desta decisão nasceu da attitude da sua gente para com as mulheres indigenas.

"Provavelmente instigada pela ardencia tropical pozse a gente phlegmatica das praias do Zuyderzee a galantear com o bello sexo local. Tambem cortou logo Roggewyn o mal pela raiz. Impediu a bordo as guarnições e castigou os galanteadores, "como haviam merecido".

"Mas apesar de tudo viviam os sebastianenses alarmados com a incommoda presença dos extrangeiros.

"Percebiam os hollandezes que, á noite, havia sempre sentinellas em diversos pontos. E notavam que por diversas veses occorreram em terra rebates que provocavam a mobilisação geral dos homens validos.

"Complicou-se a situação com a subita e inesperada presença de um navio de guerra do Rio de Janeiro.

"Informado pelos desertores da esquadrilha que esta se destinava ás terras austraes, resolvera o governador fluminense atrapalhar quanto possivel tal projecto que o contrariava.

"Assim ordenara ao seu preposto sebastianense que deixasse de fornecer viveres aos hollandezes e os intimasse a abandonar quanto antes as aguas paulistas.

"Si não o fizessem, dentro em breve teriam de se avir com a divisão naval da Guanabara, a qual se compunha de cinco ou seis naus de linha.

"Não se deixou Roggewyn intimidar. Tornou-se até gangento, embora reiterasse que o seu plano era visitar

(22). - Dr. Afonso de E. Taunay - Anais do Museu Paulista, vol. IV, pág. 329. 
as costas do Chile e do Perú, não querendo de todo fazer mal aos portuguezes.

"Pretende Behrens que estes não atacaram a sua esquadrilha porque viram quanto ella estava bem armada.

"Afinal tudo acabou bem. Pagaram os batavos, em mercadorias europeas, tudo quanto de repastos, legumes, fructas e gado compraram, dando em troca armas, chapeos, roupa branca, manteiga, meias de seda, bebidas alcoolicas, etc.

"Pensou Roggewyn, ao partir, em dar uma demonstração de força. Reclamou mais uma vez a entrega de seus desertores. Não tendo sido attendido, achou melhor, comtudo, não arrancar os transfugas pela violencia.

"Assim, zarpou de São Sebastião na melhor harmonia com o bom povo daquelle porto. "O governador e todos os seus administrados nos exprimiam quanto nos estimavam, agora, e quanto haviam feito temerario e erroneo juizo a nosso respeito".

"Duras como eram as leis daquelle tempo, resolveu Roggewyn não perdoar ao grumete faltoso já tão duramente castigado. Assim passando por uma ilha deserta, a tres leguas ao sul de São Sebastião, ordenou que lá o deixassem.

"Que destino terá tido este Robinson inedito da nossa ainda hoje selvatica e deserta Ilha dos Alcatrazes?" (23).

Sôbre o importante assunto encontramos alguns documentos inéditos nos maços de papéis da antiga Vila, recolhidos ao Arquivo do Estado. São os ofícios do sargento-mor Manuel Gomes Marzagão e do capitão Diogo de Escobar Ortiz, que em parte confirmam as asserções de Behrens, como verão os leitores.

A presença dos navios corsários naquele pôrto da Capitania, teria ocorrido de outubro para novembro do ano de 1721 .

Dizia o comandante da Vila em seu ofício dirigido ao Governador da Capitania:

"Tenho avisado por varias veses a V. Exa. da chegada de tres navios Olandezes no porto desta Villa, e athé ao presente não tenho tido reposta e hoje que se contão vinte e sete do corrente me vi tão importunado com o ofisial Olandez que veio a terra por mandado do seu comandante e me fez um protesto de queicha que contra mim avia de fazer por eu lhe não comseder comprar refresco para os seus doentes atroco dos seus efeitos, e que em nenhuma p.e se tinha uzado com elles, o que aqui tinhão exprementado, eq. não trazião idr.o de nenũa sorte para delle se vale. rem, e que serta m.te lhe morreria m.ta gente doente que 
traziã, e que pello amor de noso Deos lhe Largaçe ao menos seis rezes para serremediarem, athé porençe na barra de Santos, e que me querião deichar trinta espingardas de_ penhor que dellá as mandaria buscar, e dezempenhar, com o dr.o que o senhor go.r de Santos lhes ofereceu emprestarlhe, e porvar a sua comtumazia, e Enquerir o seu dizer de tres homens que the fugio dos seus navios dizereme que herão de paz, e q. este hera opr.o porto, que tinhão tomado de. pois que de sua terra sahirão, e dizerem-me que hera serto, o trazerem m.tos doentes, e resear Eu que de nesesidade desem algũa assaltada em algum sitio honde ouVeçe gado, honde Eu não poderia socorrer atempo de lhe atalhar o emtento por fiquar instancia os sitios desta villa, lhe aceitei as d.as trinta espingardas pelas seis rezes que the mandei dar, e coatro que ja lhe tinha mandado dar, no principio da sua chegada, por logo me pedirem fiado, emq.to tinha resposta do aviso que fiz a V. Exa. e tambem emy.to Eu me entrincheirava e se me ajuntaçe os moradores que me apanhou achegada dos d.tos tão subitam.te que só me achei com o C. da Ordenança Diogo de Escovar Ortiz, e quinze homens asistentes nesta villa $\mathrm{e}$ as d.tas dez rezes emportarão sento e vinte e sinco mil reis que portanto deicharão empenhadas as d.tas Espingardas sendo Causo que os ditos, não mandem da Villa de Sanctos, o dr.o para se satisfazer aos donos idas rezes, decidi fazer pagam.tos com as mesmas Espingardas que não heide dispor delas athé ahorde de V. Exa. e pellos mesmos Olandezes, escrevi aos srs. go.res de Sanctos relatando-lhe o so_ cedido. Tambem lhe dou p.te a V. Exa. que me acho de prez.te com noventa e seis homens capazes de pegar armas, e só sesenta, e oito armas de foguo, que como são homens pobres, não tem posibilidade para poder comprar, e como he tão nesesario, veja Vosa Exa. se me pode socorrer com armas de pederneiras de Sua Mag.e que Deos G.de para este moradores, que estão sem ellas, se valerem dellas em semelhantes ocasioins; com esta remeto ao Sr. G.or de Sanctos dous Olandezes dos que fugirão p.a remeter a Vosa Exa. e fiqua hu por emcapaz, em.to enfermo de hua perna que se escapar seguirei a horde de $V$. Exa. O ofisial olandez que veio a terra, prometeu-me de sahir fora deste porto para o de Sanctos aos vinte e nove deste mez, que como estauão dando Lados, o não podião fazer mais breve não tenho de que mais avizar a $V$. Exa. mais que esperando m.tas ocasioins dos serviços de Sua Mag.e q. Deos g.de para a ellas não faltar e de V. Exa. como devo São Seb.am 27 de no.bro de 1721 annos. (24).

\section{Umilde Subdito de V. Exa. \\ Manoel Gomes Marzagão}

Illm. Sr. Gn.al.

(24). - Arquivo do Estado, Maço 23, pasta 1, doc. 3. 
Também o capitão Diogo de Escobar Ortiz, tendo em vista a presença dos navios holandeses em São Sebastião, dirigia-se ao Governador da Capitania, fazendo ver quanto êsse fato os preocupava, pela insuficiência da fôrça de que dispunham para que pudessem repelir qualquer ataque que por acaso fôsse levado a efeito contra aquela vila.

Dizia então:

\section{Exc.mo S.or}

Por Vezes tem dado o sarg.to Mor M.el Gomes Marzagão p.te a V. Excla. da chegada de tres navios Olandezes, q. anchorarão neste porto desta V.a q. nos tem dado bem q. entender: e como obrigados da necesid.de pela pouca força com q. nos achamos, se lhes concedeu a instancia de repetidas vezes alguas rezes, por termos tempo de nos entrincheyrar, e de recolherem a esta V.a todos os moradores; e haver tempo de dar p.te a V. Exc.la, como ditto he: até o prez.te não temos tido resposta, e os navios inda ficão prez.tes.

Tambeu dou p.te a V. Exc.la q. dando eu rebate assim q. se avistarão os navios; p.a q. acodissem todos os moradores, acodirão tambem dous capitaens das barras, e não querendo tomar as minhas ordens hia sendo motivo de dezunião entre nós: e assim peço a V. Exc.la seja servido mandar-me o regim.to p.a me poder reger, e saber qual he a minha obrigação; por excuzar outra turbação semelhante: como tambem dou p.te a V. Exc.la de como não ha nesta V.a hua caixa de guerra nem hũa alabarda; q. hũa e outra couza mandey vir da Cid.e do Rio de Janeiro; e importou vinte e quatro mil reis; e se sua Mag.de q. Deos g.de dá faculd.de p.a q. de sua real faz.da se de esta ajuda de custo, com ordem de V. Exc.la serey pago, ficando sempre m.to prompto p.a o serviço de sua Mag.de q. Deos g.de e de V. Exc.la V.a de S. Seb.am Hoje 28 de Novembro de 1721 annos".

Soldado de V. Exc.la.

Diogo de Escobar Ortiz" (25).

Felizmente, atendendo à intimação que the havia sido feita, resolveu o almirante Roggewyn deixar o pôrto, retirando-se para o Sul.

Sòmente, depois disso, voltou a tranqüilidade ao seio dos habitantes daquela vila.

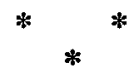

(25). - Arquivo do Estado, Maço 23 (T. C.), pasta 1, doc. 4. 


\section{A PESCA DE BALEIAS.}

Já em uso em outros pontos de litoral do Brasil, não deixod também a pesca de baleias de ser estabelecida nas costas desta Capitania, com a instalação de vários centros ou "armações", para onde eram os cetáceos recolhidos, aí procedendo-se ao aproveitamento das barbatanas e do azeite.

Em São Sebastião teve assento uma das mais importantes dessas armações do litoral paulista, sendo avultado o número de homens empregados nesse mister.

Outras ainda foram estabelecidas em vários pontos, como na Bertioga, na Barra Grande (Santos) e na ilha do Bom Abrigo, em Cananéia.

Dentre tôdas, a da Bertioga parece ocupar o primeiro lugar, pois segundo uma informação prestada pelo Capitão-General, $\mathbf{D}$. Luís de Souza Botelho Mourão ao Governador da Metrópole referente à pesca na Capitania de São Paulo, consta ter sido o seguinte o movimento aí observado durante o ano de 1766:

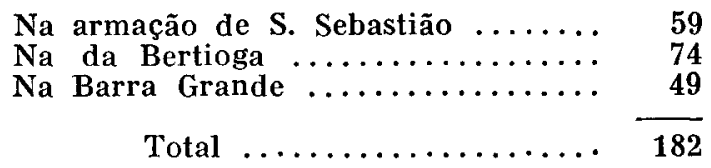

A pesca das baleias no Brasil, porém, teve lugar muitos anos antes, como provam os documentos coloniais.

Delas fizeram menção Antônio Knivet em sua narrativa da viagem feita ao Sul, na companhia de Thomaz Cavendish e José de Anchieta e seus companheiros que, das janelas do Colégio da Bahia, passavam horas inteiras a contemplá-las, vendo-as saltando sôbre o verde dos mares.

Conta Frei Vicente do Salvador, de uma baleia que dera à praia, no Rio de Janeiro, defronte do Convento do Carmo, dela se apropriando os pescadores e valendo-se de sua carne para a fabricação do azeite.

Segundo Varnhagen, a indústria da pesca das baleias comepou no ano de 1602, permitida na Bahia a certo biscainho Pedro de Urecha.

Anos depois entrava o monopólio do azeite de peixe na lista dos contratos arrematados, rendendo para a Fazenda Real de .. $600 \$ 000$ a $700 \$ 000$ anuais.

Para o Provedor-mor Cordovil da Siqueira e Melo, no Rio de Janeiro, tal contrato começou em 1644. 
Monsenhor Pizarro, diz o dr. João Vieira Fazenda, contesta esta opinião, sustentando que $\circ$ início de tais contratos teve lugar antes de 1639, e argumenta citando a verba testamenteira de certo João Loureiro Coram, que legara a seu sobrinho Miguel João, .. $100 \$ 000$ de monte-mor do espólio, por o haver servido alguns anos na armação das baleias.

E conclui o esforçado historiador, dizendo:

“Seja como fôr, está provado que, anos depois de fundado o Rio de Janeiro, os habitantes entregavam-se com ardor, à arriscada pesca das baleias que, em cardumes, vinham refrescar-se nas águas da formosa Guanabara".

Em São Paulo, sòmente mais tarde se cuidou dessa indústria, como passaremos a demonstrar.

Em 24 de dezembro de 1726 a Câmara da vila de Santos fazia chegar às mãos do governador da Capitania, uma reclamação em que dizia:

Illmo. e Exmo. Snr.

A obrigação que nos assiste de atttendermos e procurarmos o bem commum nos move a representarmos a V. Exa. a falta que nos consta e ha de azeite de peixe no estanco desta villa e rogarmos se digne V. Exa. m.dar impedir na armação da Ilha de S. Sebastião que saya azeite della para outras partes sem primr.o o administrador della fazer recolher no estanco desta V.a a quarenta pipas de azeite para o gasto dos moradores della, e dos da cidade de São Paulo até o tempo da pesca das balêas.

D.s g.de a V. Exa. m.t an.s.

S.tos em Camera de 24 de Dezembro de 1726.

D. V. Exa. m.to reverent.s servidores

Manoel da Cunha de Andrade e Souza,

José Ribeiro de Andrade,

Antônio Martins de Aguiar,

Joâo Teixeira de Carvalho, Manoel Jorge (26).

Como se depreende dêsse ofício, era do azeite extraído das baleias, que se serviam os habitantes para as suas necessidades. $\overline{\mathbf{A}}$ falta de petróleo, era êle empregado como combustível, na iluminação não só da vila de Santos, como também da Capital.

Por êste motivo explica-se perfeitamente o empênho com que era feita a perseguição aos cetáceos, que foram por isso mesmo, desaparecendo pouco a pouco.

O primeiro contrato que nesse sentido encontramos, referente à vila de São Sebastião, foi assinado por Domingos Gomes da Cos-

(26). - Arquivo do Estado, maço 10, pasta 6, doc. 13. 
ta, a 16 de setembro de 1729 , pelo qual se propunha estabelecer à sua custa

hua nova armação e fabrica de pesca de Baleyas nas costas dessa Capitania (São Paulo) por tempo de dez annos, ficando no fim dellas toda a armação e suas pertenças com doze escravos, para a Fazenda de Sua Magestade (27).

Assinado o referido contratd, iniciou Domingos Gomes da Costa os seus trabalhos, assentando os fornos necessários, construindo casas para a acomodação dos pescadores e barracões, dando logo início à pesca.

Pouco tempo durou, porém, essa atividade, porque havendo o celébre capitão general Antônio Caldeira Pimentel assumido o govêrno da Capitania a 15 de agôsto de 1727 , não tardou êle em levar ao conhecimento de Sua Majestade os inconvenientes que existiam no cumprimento de tal contrato, lesivo à Fazenda Real .

Assim foi que, em carta datada de maio de 1730, assegurava o "zeloso" governador quais as inconveniências que se seguiam de sua execução.

Uma delas, a questão de preço ou de valor do contrato; outra, a do estado imprestável das embarcações e inutilidade de tudo, quando findo o contrato, cruzados".

"em estado de não poder valer mais de 7 ou $8 \mathrm{mil}$

Alegava ainda que,

"se fazia ponderavel a da falta de lenha nas costas da jurisdição de São Paulo, que se reduziria á maior penuria, com o consummo de dez annos e ficaria inutil a fabrica promettida por Domingos Gomes da Costa, por mais bem preparada que se quizessem considerar, fasendo-se pelas razões referidas totalmente chimericas a conveniencias q. a simulação de D.os Gomes pretendia persuadir".

E entre outros consideranda, dizia mais:

"se vem a conseguir a certeza de que o projecto se encaminhava, não ao contracto dos azeites das Balêas, mas á pesca do Ouro das Minas Geraes e do das minas da jurisdição de São Paulo, lucrando o não pagar quintos de todo elle, e tambem os importantissimos interesses de introduzir nas povoações hũas, e outras Minas, e nas mais terras de hûa, e outra Provincia, todos quantos generos quizesse a sua ambição, sem serem despachados nas Alfandegas, cometendo hum furto nos quintos

(27). - Documentos Interessantes, vol. 78, pág. 278. 
do ouro q. extrahisse, e outro nos direitos q. não pagava das fazendas que introduzisse".

Como disse o dr. Antônio de Toledo Piza, o capitão-general, pouco escrupuloso quando defraudava êle mesmo o físco colonial, estava aí a julgar da intenção dos outros, parecendo julgá-los por si!

Era evidente sua má vontade para com Domingos Gomes da Costa.

Apesar disso, ordenava el-rei, por seu Conselho Ultramarino, em 3 de março de 1723, que sem embargo das dúvidas apresentadas, se pusesse o dito contrato em execução.

Entretanto, tão grande foi o "zêlo" do Governador, que, em atenção às denúncias apresentadas, resolveu $\mathrm{D}$. João mandar em 15 de maio de 1733 fôsse "substado" o estabelecimento da pesca de baleias "na costa da Capitania".

Grandes foram os prejuizos alegados pelo contratador, sem nada conseguir.

Alguns anos depois, outro contrato nesse mesmo sentido era firmado por Francisco Peres de Souza, por seis anos apenas,

"em preço cada anno de quarenta e oito mil cruzados, e cem mil reis livres, para a Fazenda Real, a saber: vinte e oito mil cruzados, pela de Santa Catharina; e dez pela de São Sebastião, Santos e São Paulo", -

que deviam ser satisfeitos na Provedoria de Santos.

Esse contrato foi aprovado por Alvará de 27 de dezembro de 1754 e registrado em 31 do mesmo mês, a fls. 37 do livro $3 .^{\circ}$ de Contratos do Conselho Ultramarino.

Estabeleceram-se as armações e iniciaram-se os trabalhos da pesca.

Chamavam-se baleeiros os homens que saiam pelo mar, no pesado mister da caça às baleias; - baleeiros ou baleeiras, barcos ou escaleres próprios para êsse fim.

Tão duro, tão pesado era o trabalho, além dos perigos que corriam os tripulantes, que os contratos se faziam com a ajuda dos capitães-mores, que andavam em diligências pelos matos, à caça de homens para entregá-los à sanha dos administradores das armações, de onde fugiam a cada instante.

O rigor chegava ao auge. Surgiam as reclamações. Intercediam pessoas caridosas movidas pela piedade.

$\mathbf{E}$ tantas foram as queixas, que o próprio capitão-general não pôde deixar de interessar-se pela sorte dêsses infelizes. 
Em 4 de maio de 1811, representava a Câmara da vila de São Sebastião, ao capitão-general Franca e Horta, contra

"o despotico obrar de Manoel Pinto Rosado, vendedor do azeite, de que era administrador José Antônio dos Reis, sôbre as horas para a venda do mesmo".

Era costume então

"vender-se desde manhã até meio dia e das 3 ás 8 horas, nunca impugnado pelo seu antecessor Amaro Gomes Brazão".

Entretanto, passara o mesmo Rosado a sentenciar brutalmente, que

"só havia de vender durante as horas do dia", não atendendo a "retardação de muitos compradores e a ninguem attendendo depois do toque das Ave-Marias, sem attenção a qualquer pessoa publica e de bem, que lh'o havia man'dado pedir por favor".

Esse e outros fatos, haviam feito com que a Câmara, incorporada fôsse repreendê-lo.

A 11 de junho de 1819, porém, era o Capitão-mor João José da Silva Costa que se dirigia ao Capitão-General, expondo-lhe o que se passava nas armações, pelos maus tratos de que eram vítimas os baleeiros.

Receiosos de serem recrutados para tal serviço, fugiam dos seus distritos internando-se nos sertões, pois

"soffrião muito e ás vezes voltavão sem pescar cousa alguma, sendo nesse caso, obrigados ao pagamento do que comião, pois apenas percebião pelo que pescavão".

Mas não era só: eram ainda ameaçados de prisão e outros castigos, quando se negavam a rumar para o Oceano.

Não recebiam salário certo para o seu sustento, - dizia êle,

“a não ser um tanto por Balêa que pescavão, apesar de percorrerem os mares noite e dia, puxando pelos remos!"

No ano seguinte, isto é, em 1820 , voltava o mesmo a solicitar qualquer prcvidência que minorasse a vida dêsses desgraçados, pois

"sendo a pesca diminuta, acontecia não ganharem ás vezes nem mesmo com que pagassem a comida, ficando empenhados por mais tempo".

E sendo Sua Excelência

"pai desta Provincia, lançasse suas vistas sobre esse vexame, pois só as duas villas — de São Sebastião e 
Villa Bella - experimentavam jugo tão terrivel, de luctarem seus filhos ao pé de 5 mezes, sem que pudessem vêr o fructo dos seus penosos trabalhos!"

Se fugiam eram presos. E só Deus lhes conhecia os sofrimentos. cadores.

Avolumavam-se-lhe as queixas levadas pelas famílias dos pes-

E citava fatos dolorosos, rogando por um baleeiro, que fôra castigado.

Recordava

"as lagrimas de sua mulher Rosa Maria e da innocente filha e sua mãe, que lhe haviam suplicado em prol do infeliz".

Tocado pelo sentimento de piedade, ordenava o capitão-general ao Administrador que informasse sôbre as reclamações recebidas, isto é, quanto aos salários e tratamento dado aos mesmos, respondendo o contratante que isso não podia ser, pois tudo dependia da felicidade da pesca e do artigo pelo qual se governava... E não procediam as queixas, porque também

"em suas entradas", - que eram de 4 mezes, percebiam os remeiros a razão de oito mil reis; timoneiros vinte; arpoadores, $25 \$ 000$, mais $12 \$ 000$ de banquete!"

Pela arrogância com que ao próprio Capitão-General respondia o Administrador da armação, é claro de ver-se o que não experimentariam os homens recrutados para a pesca, sabendo-se que, de acôrdo com os contratos, gozavam os seus beneficiados, até mesmo do direito de poderem punir os insubmissos ou faltosos com prisões e castigos corporais...

Os contingentes encaminhados anualmente para caida uma das armações era mais ou menos de 30 indivíduos, sendo que no ano de 1820, só as armaçóes de Vila Bela e Bertioga, ocupavam 69 homens e possuiam 15 lanchas.

A perseguição impiedosa movida aos cetáceos nas costas da Capitania de São Paulo, onde funcionavam nada menos de cinco armações - São Sebastião, Vila Bela, Bertioga, Barra Grande e Bom Abrigo - deu motivo ao seu gradual afastamento.

Ainda mais, como dizia um dos capitães-generais, - à freqüência das barcas a vapor atribuia-se também o desaparecimento dêsse mamífero, das costas da Capitania de São Paulo, onde já em 1820 poucas vêzes aparecia.

Começou por isso o crepúsculo da perigosa profissão, pelo desinterêsse que então apresentava aos administradores das armações. 
Além disso, as questões políticas no Rio da Prata e a guerra de corso movida contra as embarcações que navegavam nas costas do Brasil, principalmente entre a Bahia e Santa Catarina, ocasionaram o afastamento dos barcos baleeiros dos mares da Capitania de São Paulo, pelo risco que corriam não só as mesmas embarcaçöes, como os seus tripulantes.

Das armações, como verdadeiros espectros, ainda hoje natam-se os vestígios e ruínas, conservando-se-lhes a denominação do local, para relembrar-lhes a existência tumultuosa.

São lugares assombrados, como dizem os praianos, - pontos de onde, em noites enluaradas, quando o mar molemente se espreguiça nas areias das praias, se ouvem gritos, imprecações e gemidos soturnos...

Outras vêzes, são vozes confusas e o arrastar de pesadas correntes, quebrando o silêncio da noite, num chôro convulsivo, que recorda as dôres e os sofrimentos dos que por ali passaram e morreram.

E' o protesto dos espíritos contra a maldade dos homens...

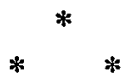

\section{A IGREJA MATRIZ.}

Dos livros que temos compulsado e dos numerosos papéis existentes no Arquivo Público, nenhuma referência ressalta sôbre a data da fundação da primitiva igreja desta vila.

Entretanto, como é sabido, para que um povoado qualquer pudesse gozar do privilégio de sua ereção à categoria de freguesia, tornavam-se necessários alguns requisitos, tais como o do número de habitações, próximas umas das outras, casas para a Câmara, quando erectos em vila e principalmente a existência da capela.

De fato, era esta o verdadeiro embriáo dos povoados: sem ela não se conseguiria a aproximação dos habitantes; era a célula mater de tôdas as povoações.

Sendo São Sebastião elevada em vila em março de 1636, é claro de ver-se que de muitos anos antes datará a fundação de sua primeira capela, mesmo porque, segundo os historiadores, a referida vila teve sua origem em fins do século XVI e princípios do século XVII, quando naturalmente devia ter sido construída a primitiva capela que deu comêço ao povoado.

E tão maltratada já se achava em 1798 , que a Câmara da vila, reunindo-se a 18 de novembro dêsse ano, tratou de reconstruí-la, 


\begin{abstract}
"convocando para isso não só os principaes da villa, como os mais abastados lavradores, afim de concordarem juntos, voluntariamente sobre a factura da nova Igreja Matriz",
\end{abstract}

visto como a que ainda existia estava

"em estario tam deploravel pella sua antiguidade que não se podia encontrar outra igual, ainda nas povoações mais inuteis e remotas desta Capitania, sendo já toda ella hum completo estrago dos tempos, e com tal indecencia para nella se conservar o Santissimo Sacramento",

que se tornava necessária uma providência qualquer.

Dessa reunião em Câmara e conseqüente aprovação pelas pessoas que a ela compareceram, foi lavrado um têrmo especial, em que se declarava a contribuição com que cada um dêles deveria concorrer anualmente

"thé complemento della", pois a "inspiriencia das outras Villas demonstrava que só por este modo se podia edificar nova Matriz, com huma voluntaria e livre concordata do Povo, sem serem para isso constrangidos, assistindo a Camara para maior solenidade de sua acceitação".

\title{
Dessa maneira se estava
}

"continuando a de Ubatuba, impetrando aquella Camara o beneplacito do antecessor de S. Exa. E como das religiosas intenções de $S$. Exa. estivessem todos bem certos, por se tratar do culto de Deus, rogavam-lhe para que houvesse por bem consentir e approvar aquelle acto, afim de que, no decurso dos annos ninguem pudesse fugir a aquella obrigação".

"A causa toda hé de Deus e por isso com mais confiança esperamos o beneplacito de V. Exa. e oridem para fazermos cumprir as condições do termo assignado".

Era a Câmara de então composta dos juízes ordinários, Matias Soares de Novaes, Manuel de Jesus Pedroso, Rafael Pinto da Rocha e Tomás Romão César.

Alguns anos depois era contratada a construção, entre o capitão-mor e o mestre pedreiro Manuel Álvares de Abreu, da

\footnotetext{
"obra da nova Igreja Matriz, que com muito zelo estava sendo principiada".
}

Seria isso mais ou menos no ano de 1816 , pois o documento a que nos reportamos não vem datado, porém, outro, que foi informado em 28 de janeiro de 1816 , referindo-se ao contrato, diz haver sido o mesmo realizado com o capitão-mor João José da Silva Costa.

Ora, o referido oficial das Ordenanças sòmente foi promovido a êsse pôsto no ano de 1814 , de onde se conclui que a obra da 
nova Matriz devia ter sido começada nesse mesmo ano, porque até então, João José da Silva Costa era apenas capitão de Ordenança.

Entretanto, é possível mesmo que tal fato houvesse ocorrido entre os anos de 1809 a 1810 , porque o documento a que nos referimos declara haver sido o mesmo contrato assinado, de "cinco para seis anos".

No caso vertente, aliás, não nos interessa a precisão dessa data, porque, apesar de tudo a única coisa que na realidade se fêz, foi a cobrança das ofertas, não tendo sido iniciada a construção do templo.

Manuel Alves de Abreu, imaginando maiores lucros e desejoso de conseguir gratuitamente a pedra necessária, procurou entender-se com o padre Faustino José Bravo, que autorizou-o a extraíla de uma pedreira de seu pai, o que levou o proprietário a protestar perante o govêrno contra semelhante ato.

Alegava o empreiteiro que as pedras em questão seriam para Igreja"

"ornamento, serventia e semetria da mencionada

e que o dono da pedreira exigia-1he então um "novo pacto" para conceder-lhe tal autorização.

E acrescentava:

" $O$ sup.e vendo que sem.e arbitrio desdoura muito a primr.a acção de generosid.e que os donos da pedreira ozarão p.a com a nova Caza de Deos, e assim mais o alto prejuizo q. vai redundar, tanto no atrazo do edificio como no mais q. pode sobrevir a huma obra por todos os principios santissima e m.to necessaria seu completam.to ao Congresso dos Catholicos q. gemem por verem a Santa Religiam envergonhada por celebrar seus divinos officios em hûa Igreja m.to velha m.to arruinadissima e m.to indecente p.a aquelles acttos e m.to mais p.a se conçervar no seu ceio o Augustissimo Sacramento da Eucharistia como por tantas pastoraes do primr.o chefe do rebanho de Jezus Christo desta Capitania tem sido lamentablo seu deploravel estado.

Portanto o Sup.e cercado de duros obstaculos lancase aos pés de V. Exx.cia afim de que a actual obra da nova Igr.a senão atraze pello impedim.to que os donos da pedreira ofereçem ao Sup.e conhecendo v. Ex.ca aprecizão que dellas ha.

Cheio pois o Sup.e de esperança.

P.a V. Ex.cia

havendo consideração a que neste Paiz não há obras de Cantaria. V. Ex.cia mande pello seu Respeitavel despacho o que vir ser mais justo a bem do Servisso de Deos.

E. R. M.

Manoel Alz. de Abreu". 
Procurando harmonizá-los, intercedia o Capitão-Gneral, oficiando ao Governador da Vila, o coronel Francisco Inácio, para que o informasse do que havia.

Dirigindo-se êle ao dono da pedreira, disse-lhe o mesmo em suas alegações, por escrito, serem

"falsas as razões expostas pelo contractante Manoel Alvares de Abreu".

O dono deste roxedo - escrevia - nunca foi fallado para esta gratuita acção, mas sim hum seu filho, o P.e Faustino Bravo, que pensava que a obra seria feita a jornal, não de empreitada".

Mas quando soube ter sido a mesma

"contractada por dezasseis mil cruzados e que a pedra necessaria para a dita obra foi justa por dois mil, pouco mais ou menos, pelo nobre Senado, com o Capitam Mór desta Villa, cuja quantia recebera, - "entâo recusara dál-a gratuitamente, pois nesse caso "já não hia favorecer á Igreja, mas sim engrossar o cabedal de particulares...".

Se não houvesse dinheiro para cobrir tal despêsa,

"na villa ainda existiam pessoas idoneas, que poderiam esmolar para esse fim, uma vez que nấo bastavam o grande tributo annual que os freguezes da Igreja pagavam ha doze annos mais ou menos, e o donativo dos libertos, que por si pagavam 80 reis e dos captivos na importancia de 160",

quando o pedreiro em coisa alguma concorria .

Se, se tratasse de esmola, nenhuma dúvida oporia, estando mesmo pronto para acudir com

"seus carros e escravos, mas nunca para quem não precisava della".

"O sabio, e piedoso Despaxo do Ill.mo e Ex.mo Senhor Conde General bem mostra não querer mais do que aquilo que hé possivel e V. S.a não ignora a numeroza familia, que sustento em huma idade avançada, não tendo outras rendas mais do que o trabalho quotidiano; esta familia, Templos vivos do Espirito Santos a roda de hum Pai encanecido, e doente, são motivos bastamtes para mover o coração terno, e piedozo, o coração Paternal do Ill.mo e Ex.mo Senhor Conde General, afim de aliviar-me de hoje em diante e a todos os meus filhos e filhas do mencionado Tributo annual para a factura da nova Matriz, huma vez que eu por me conformar com a sua vontade dê gratuitamente a pedra para os portais, obrigando-se o Mestre Pedreiro a todo e qualquer damno que aconteça em plantas ou Cazas com a tirada da pedra. 
Sem embargo de todo o exposto fico prompto para obedecer a tudo quanto o Ill.mo e Ex.mo Senhor Conide General haja por bem dicidir sobre isto.

Tal hé a resposta, que com toda a submissão, e respeito tenho a honra de appresentar a V. S.a aquem Deos guarde por muitos an.os.

\section{Domingos da Costa Ribr.o".}

As alegações tanto de um como de outro, foram informadas em 28 de janeiro de 1816 pelo coronel e governador da vila, que, em resumo, afirmava:
a) terem sido as obras da nova Matriz começadas pelo mestre pedreiro Manoel Alves de Abreu, sendo o seu preço contractado por $16 \mathrm{mil} \mathrm{cru-}$ zados;
b) haver "o capitão-mór vendido as pedras pelo preço de 2 mil cruzados, de que logo recebeu o dinheiro".

Dêsse incidente, motivado por interêsses pessbais, resultou ser sustada a construção da Matriz, pelas graves acusações levantadas contra o empreiteiro.

A 11 de novembro de 1819, a Câmara da vila participava ao Capitão-general os fatos ocorridos em 1815 com o contratante, que também havia construído a de Ubatuba, a qual,

"estando a construcção em andamento, aconteceu desmoronar-se por falta de segurança nos alicerces".

"Em 1816, - dizia a edilidade sebastianense, - desconfiados, Povo e Camara, do prestigio desse empreiteiro, suspenderam-lhe os pagamentos, não the dando mais dinheiro para a continuação das obras que ficaram interrompidas, até que, chegando á villa como vigario collado, o reverendo Bernardo da Pureza Claraval, e achando a Matriz antiga pouco decente, tentou reconstituil-a com o auxilio do povo e mesmo algum dinheiro que possuia e mais uma contribuição de $40 \$ 000$ da propria $\mathrm{Ca}$ mara".

Tendo sido excluído do serviço por incapacidade, fêz o mesmo empreiteiro vários requerimentos à Câmara, que não foram deferidos e bem assim pediu para que fôsse levada a efeito uma vistoria na parte concluída, o que não foi possível fazer-se nessa ocasião

"por não haver na terra professores daquella arte", realizando-se mais tarde ou fôsse aos 11 dias do mês de novembro de 1819 , servindo de peritos os pedreiros capitão Atanásio Marques e Inácio Corrêa, 
"professores ido dito officio",

com a presença do vigário colado e testemunhas.

Para isso abriram em tôrno do alicerce "quatro cavas" até a profundidade de cinco palmos e meio e de grossura ou largura seis palmos menos três dedos craveiros, - e em partes cinco palmos e meio e muito mal fabricado por não estarem traçadas as pedras se não scbrepostas umas sôbre as outras, que com as mãos se estavam desmanchando, por estar fabricado com barro e areia e muito pouca ou nenhuma porção de cal, de forma que nas mesmas cavas e buracos que se abriram logo que o alicerce ficou desamparado da areia que se cavou entraram a despregar-se e a cair as pedras do mesmo alicerce, pelo que declararam ser impossível continuar na referida obra porque não tinha alicerce competente para isso, porquanto naquele lugar de areia era necessária a profundidade de dez palmos e ser estacado com madeiras por baixo, e pelos lados com cal e saibro competente, bem traçado e precisava mais um palmo de grossura, ao menos, visto ter de vão a Igreja que se pretendia fazer, cinqüenta e dois palmos de largura e vão e que no caso de se levantarem as paredes arribas, não poderia, sustentar o pêso das mesmas paredes pela fraqueza dos alicerces e antes de se deitar a madeira em cima, haviam vir abaixo, quanto mais suster o pêso do telhado e pela referida causa em suas consciências não davam valor algum ao dito alicerce e terminavam declarando que o empreiteiro

"não tinha capacidade nem intelligencia para se encarregar della".

Do que fica exposto se conclui claramente que a Igreja Matriz de São Sebastião, construída modestamente no alvorecer da antiga vila, foi reformada ou reconstruída no ano de 1816 pelo vigário colado Bernardo da Pureza Claraval, que logo "pôs a mesma obra em execução", não aceitando a proposta feita pelo construtor Manuel Álvares de Abreu, oferecendo-lhe duzentos mil réis para permitillo poder prosseguir nas mesmas.

Era o subôrno.

Revoltado com êsse fato, declarou-lhe o honesto vigário, que

"se não embaraçaria nisso, visto que sua intenção era reedificar a Igreja velha, para a administração do divino culto, e o povo e a Camara, que edificassem a nova, quando pudessem e quizessem, porque não seria a mesma para os seus dias". 
E assim foi derimida a questão sem maiores sacrifícios para a população, concorrendo o vigário com seus próprios recursos para a renovação do antigo templo.

$$
* * *
$$

\section{DA MINERAÇÃO E CONTRABANDO DE OURO.}

A descoberta de minas de ouro foi a maior preocupação dos primeiros povoadores do Brasil.

Já Martim Afonso de Souza, levado pela idéia de alcançar o E1-Dorado, que se dizia estar localizado no interior do Rio da Prata, procurava encontrar uma brecha, uma entrada, por onde pudesse penetrar no sertão. E vislumbrando-o no ponto de depressão da Serra do Mar, defronte de Cananéia, daí fêz expedir a $10^{\circ}$ de setembro de 1531 a malograda bandeira de Pero Lobo, em procura de ouro e prata e da qual nunca mais houve notícias, presumindo-se que fôsse trucidada pelos carijós junto às margens do Rio Iguaçú.

De então por diante, foi sempre essa a idéia fixa dos habitantes de tôdas as regiões do Brasil.

Sendo assim, não era admissivel que os moradores das vilas da Marinha se desinteressassem da mineração.

De todos os pontos da costa partiam grupos de homens que examinavam os vales, rios e ribeirões na espectativa de largos proventos.

Quando o capitão-general D. Rodrigo César de Menezes em 1721 assumiu o govêrno da Capitania, tendo conhecimento de que os moradores das vilas de São Sebastião e Ubatuba

\footnotetext{
"intentavam fazer experiencias por descobrimento de ouro por haver nas serras dellas alguas amostras"
}

mandou publicar um bando proibindo a continuação dêsse trabalho, o que levou el-Rei a escrever-lhe ordenando que suspendesse semelhante ordem pela

"conviniencia que poderiam tirar os moradores que iam faiscar" e os deixasse em paz, pelo interesse que poderiam "dar de sy os taes descobrimentos".

A 14 de fevereiro de 1722, oficiava a Câmara da Vila de São Sebastião ao Governador, comunicando-lhe a descoberta de alguns ribeirões onde haviam sido encontradas pintas de ouro por Manuel Lopes de Medina (28).

(28). - Arquivo do Estado, maço 10, pasta 3, doc. 2 . 
Interessavam-se os sebastianenses pela mineração, quando em 1727 assumia D. Antônio Caldeira Pimentel o cargo de Governador da Capitania.

Bem conhecido se tornou êste capitão-general, em virtude do excessivo zêlo com que tratou da arrecadação dos dizimos e principalmente por causa das queixas levantadas contra si pelas dificuldades criadas pelo seu govêrno.

Já por essa ocasião, segundo rezam os documentos, era vultosa a quantidade de ouro exportado pelos portos de São Sebastião e Ubatuba.

O General Caldeira Pimentel, que não perdia ocasião para a tudo se opor, embaraçou até mesmo a pesca das baleias em São Sebastião, proibindo ao contratador da mesma continuar a exercer êsse mister, alegando ser outro o fim a que se propunha o referido contratante, qual fôsse o do contrabando do ouro!

Semelhante questão explanamos já, em o capítulo anterior, ao tratarmos da mesma pesca e dos prejuízos sofridos por Domingos Gomes da Costa.

Das denúncias levadas ao Vice-Rei e dêste ao govêrno da metrópole, resultou a carta seguinte:

Dom João por graça de Deus Rey de Portugal, e dos Algarves daquem, e dalem mar em Africa Snor de Guiné, etc.

Faço saber a vos Antonio da Silva Caldeira Pimentel Governador da Capitania de São Paulo, que vendo-se o que se me escreveo o Prov.or do Rio de Janeyro Luiz Vahia Monteiro em carta de vinte de Mayo do anno passaido sobre o muito ouro, que pellas Villas de Ubatuba e São Sebastião embarca estrahido das Minas-geraes pela Villa de Guaratinguetá

Me pareceu ordenar vos ponhaes todo o cuidado em evitar a extracção do d.o ouro pela parte que a aponta o Governador do Rio de Janr.o El Rey nosso Snr. o mandou pelo D.or M.el Frz. Varges, e Gonçalo Manoel Galvão de Lacerda Concelheiros do seu Conc.o Ultr.o, e se passou por duas vias. 'Antonio de Souza Per.a a fez em Lisboa Occídental em seis de Fevr.o de mil settecentos e trinta e hum. O Secretario M.el Caetano Lopes de Lavre a fes escrever e assignou o Conselheiro Alxeandre Metello de Souza Menezes. - M.el Frz. Varges. - Alex.e Metello de Souza Menezes (29).

Bem longa foi a correspondência trocada entre as autoridades, sôbre o

"descaminho do ouro pelo porto de São Sebastião".

(29). - Documentos Interessantes, vol. 24, pág. 45. 
No volume 54 dos Documentos Interessantes para a História e Costumes de São Paulo, vêm ainda citados vários documentos inéditos existentes no Arquivo Nacional.

Na relação Correspondência dos Governadores do Rio de Janeiro com diversas autoridades. (1718-1763), encontram-se referências sôbre cartas do mestre do Campo Matias Coelho de Souza, a Gomes Freire de Andrade (1739), sôbre bilhetes de Capitação para São Paulo e contrabandos em São Sebastião.

A fama das riquezas existentes nas Minas Gerais e o pouco resultado que auferiam os mineradores nas Vilas da Marinha, fêz com que numerosos habitantes da região transpondo a cordilheira marítima partissem para 0 interior, abandonando as pesquisas a que vinham se dedicando.

Várias foram as bandeiras de que fizeram parte os filhos do litoral, havendo algumas delas que foram organizadas e dirigidas exclusivamente por gente da marinha, como a que teve por chefe - capitão Francisco Nunes Pereira, que descobriu a antiga cidade hispano-guarani de Vila Rica e explorou o Rio Piquirí, indo depois em socôrro de Iguatemí.

De São Sebastião, muitos foram os que se incorporaram às bandeiras paulistas, marchando não só para Minas como para o Cuiabá.

Assim, abandonando as investigações iniciadas, não mais se preocuparam com a mineração ern suas terras dirigindo-se resolutamente para o sertão da Capitania, que thes proporcionava melhores resultados.

Apesar disso, entretanto, rigorosa continuava a fiscalização das autoridades, no sentido de ser evitado o contrabando de ouro pelos portos referidos, fiscalização essa que chegou não só aos tempos imperiais como aos nossos dias.

Para os cargos de Guarda-Mor das terras minerais de São Sebastião foram nomeados Manuel da Silva Salinas e Francisco Cardoso Borba, por provisões de 18 de dezembro de 1788 e 7 de dezembro de 1789, respectivamente, bem como José Garcia de Oliveira, em 18 de dezembro de 1788, para igual cargo no Rio do Gentio, na mesma Vila.

(Continua no próximo número). 